\title{
Frailty and 10-Year Mortality in Community-Living Mexican American Older Adults
}

\author{
James E. Graham ${ }^{a}$ Soham Al Snih ${ }^{a, b}$ Ivonne M. Berges ${ }^{a, b}$ Laura A. Ray \\ Kyriakos S. Markides ${ }^{b, c}$ Kenneth J. Ottenbacher ${ }^{a, b}$ \\ ${ }^{a}$ Division of Rehabilitation Sciences, ${ }^{b}$ Sealy Center on Aging and ${ }^{C}$ Department of Preventive Medicine and \\ Community Health, University of Texas Medical Branch, Galveston, Tex., USA
}

\section{Key Words}

Aging $\cdot$ Frail elderly $\cdot$ Hispanic Americans $\cdot$ Minorities .

Survival

\begin{abstract}
Background: The older Hispanic population of the United States is growing rapidly. Hispanic older adults have relatively high-risk profiles for increased morbidity and disability, yet little is known about how the construct of frailty is related to health trajectories in this population. Objective: The purpose of this study was to examine the relationship between frailty and 10-year mortality in older communitydwelling Mexican Americans. Methods: Data were from the Hispanic Established Populations for Epidemiologic Studies of the Elderly and included 1,996 Mexican Americans, aged 65 and older, living in the southwestern US. Primary measures included mortality and a 5-item frailty index comprised of weight loss, exhaustion, walking speed, grip strength, and physical activity. Results: Mean baseline age was 74.5 years (SD 6.1) and 58.5\% were women. Baseline frailty assessments yielded the following distribution: $44.9 \%$ non-frail, $47.3 \%$ pre-frail, and $7.8 \%$ frail. Overall, 892 (44.7\%) participants died during the 10-year study period. Hazard ratios (HR), adjusted for sociodemographic, health, and medical factors, demonstrated increased odds for mortality
\end{abstract}

in the pre-frail ( $\mathrm{HR}=1.25,95 \%$ confidence interval, $\mathrm{Cl}_{95 \%}$, 1.07-1.46) and frail ( $\left.\mathrm{HR}=1.81, \mathrm{Cl}_{95 \%} 1.41-2.31\right)$ groups compared to the non-frail cohort. Conclusion: The 5 -item frailty index differentiated odds of 10-year mortality in older community-dwelling Mexican Americans. This clinical index has the potential to identify older minorities at risk for poor health outcomes and mortality.

Copyright $\odot 2009$ S. Karger AG, Basel

\section{Introduction}

The concept of frailty is receiving increased attention in the research literature as the US population continues to age. The most dramatic growth in the US population over the next 20 years will be in those 85 years and older $[1,2]$. This segment of the older adult population is most likely to be hospitalized, to have disabilities and to consume a large portion of health care resources [1].

Hispanic adults are projected to be the largest minority older population by 2050 , comprising approximately $18 \%$ of the population $\geq 65$ years $[3,4]$. It has also been reported that community-dwelling older adults over the age of 65 years of Latino descent are more functionally impaired compared to whites and blacks [5]. The impact of the projected ethnic shift in the older adult population

\section{KARGER}

Fax +4161306 1234

E-Mail karger@karger.ch

www.karger.com (c) 2009 S. Karger AG, Basel

0304-324X/09/0556-0644\$26.00/0

Accessible online at:

www.karger.com/ger
James E. Graham

Division of Rehabilitation Sciences, University of Texas Medical Branch 301 University Boulevard

Galveston, TX 77555-1137 (USA)

Tel. +1 409747 1634, Fax +1 409747 1638, E-Mail jegraham@utmb.edu 
on the demand for health care services is poorly understood, particularly in those 80 years and older $[1,6]$. Hispanic older adults are reported to have higher rates of disabilities and also report poorer health status than nonHispanic whites [7].

The construct of frailty is increasingly being used to identify persons in the older population at risk for disability and morbidity [8-11]. In the aggregate, the literature suggests that frailty (1) is a consequence of multisystem dysfunction; (2) increases one's risk of disability, institutionalization, and mortality; (3) is a dynamic (fluctuating) phenomenon, and (4) is more prevalent with advancing age [10, 12-14]. Fried et al. [15] described frailty as a syndrome within the context of a theoretical model termed the 'cycle of frailty.' They operationalize the term by providing a standardized 5-item index from which the relative frailty status can be determined. Prior studies have reported significant associations between mortality and measures of frailty in cohorts of non-Hispanic white older adults $[15,16]$. Little research has been conducted examining the components of frailty in the Hispanic older adult population despite the fact that this population is known to have higher rates of diabetes and obesity, which are risk factors for increased disability and morbidity $[17,18]$.

The purpose of the current study was to determine the ability of a widely used measure of frailty [15] to predict 10 -year mortality in a large population-based sample of Mexican American older adults. We hypothesized that persons with higher frailty index scores would demonstrate greater odds of mortality over a 10 -year period.

\section{Methods}

\section{Sample}

Data were from the Hispanic Established Populations for the Epidemiologic Studies of the Elderly (EPESE), a longitudinal population-based study of community-dwelling Mexican Americans aged 65 years or older [19]. The sample was selected from the five southwestern states (Texas, California, Arizona, Colorado, and New Mexico). These states included 85\% of the Mexican American population aged 65 and over living in the US when the survey began in 1993. A multistage area probability cluster design involving systematic selection of counties, census tracts, and households was used to select the original sample $(n=3,050)$. This procedure assured that the sample was representative of the approximately 500,000 older Mexican Americans living in the southwestern US. The sampling plan has been described in previous publications $[19,20]$.

The current dataset covers the 10 -year period from wave 2 (1995-1996) through wave 5 (2004-2005) of the Hispanic EPESE. Data collected at wave 1 of the Hispanic EPESE (1993-1994) did not include all components of the frailty index. At each wave (ap- proximately 2-year intervals), data were collected from in-person interviews and performance evaluations. The subjects were interviewed and examined in their homes by raters who received $20 \mathrm{~h}$ of training in assessments of physical functioning including balance, gait, and functional daily living skills. The interviews were conducted in Spanish or English, depending on the participant's preference. The University's Institutional Review Board on $\mathrm{Hu}$ man Protection and Research Ethics approved the study.

Since the frailty index contains both physical performance and self-reported performance measures, participants requiring the assistance of a proxy $(n=272)$ were dropped from the study. An additional 57 participants were lost at follow-up (i.e. wave 2 was their last interview) and 113 had missing data on more than 2 of the 5 frailty items. On average, those excluded from the analysis were older, had lower body mass index (BMI) and cognitive functioning, reported more depressive symptoms, comorbid conditions (heart attack, stroke, cancer, and hip fracture), and difficulties with basic activities of daily living (ADL) and instrumental ADL (IADL), and were more likely to rate their overall health as poor. Limiting the sample to those with valid measurements on 3 or more of the 5 frailty items matches the approach originally used by Fried et al. [15]. Comparing those with 1 or 2 missing items to those completing all 5 frailty items yielded similar results as the comparison between excluded and included participants described above, with three exceptions: no differences in BMI, or prevalence of heart attack and cancer. Excluding people with 1 or 2 missing items did not change the significance or conclusion for any variable in our analysis so they were retained in the final sample, which included a total of 1,996 participants.

\section{Measures}

Mortality. Reported deaths over the 10 -year study period were obtained through personal contact with relatives. Confirmation and official dates of death were collected from the National Death Index files. They are a computerized index of death records established by the National Center for Health Statistics to provide mortality data for health research.

Frailty. Frailty was assessed with a 5-item scale originally developed by Fried et al. [15]. Each item was scored dichotomously (0 vs. 1) based on an individual's performance or response relative to predefined thresholds. The total score was recorded as the sum of all five items (range: $0-5$ ). Persons receiving a score of 0 were classified as non-frail, scores of 1-2 as pre-frail, and scores of 3-5 as frail. The index items included weight loss, exhaustion, walking speed, grip strength, and physical activity. We followed the guidelines and procedures established by Fried et al. [15] with three exceptions. First, the original frailty index used the Minnesota Leisure Time Activity Questionnaire [21] as a measure of physical activity. We used the Physical Activity Scale for the Elderly [22]. Second, we used different threshold values to indicate positive scores (lowest quintile) for hand grip strength. BMI is used to adjust for hand grip strength and the BMI quartiles from our sample were slightly different from those reported by Fried et al. [15]. Differences in BMI between Mexican Americans and non-Hispanic whites are well documented $[23,24]$. Lastly, we used a 4.9-meter fast-pace walk to evaluate walking speed rather than the 4.6-meter usual-pace walk initially described by Fried et al. [15]. Similar modifications of the original cutoff points and metrics have been reported by Gill et al. [16]. Table 1 provides descriptions of the items, thresholds, and corresponding percentages for our sample. 
Covariates. Sociodemographic factors included age, gender, BMI, and marital status. Age and BMI were used as continuous variables. Marital status was coded dichotomously: not married (0) versus married (1). Medical conditions included self-reported physician diagnosis of heart attack, stroke, hypertension, cancer, hip fracture, or diabetes. Self-reported smoking status (current smoker) was also obtained. Medical conditions and smoking status were coded dichotomously: no (0) versus yes (1). Functional independence was evaluated through self-reported difficulties with basic ADL and IADL. Specifically, participants were asked if they needed assistance with any of 7 ADL tasks (bathing, dressing, eating, grooming, walking across a small room, transferring from bed to chair, or toileting) and if they were limited in any of 10 IADL (using a telephone, taking medications, preparing meals, managing money, performing light housework, doing heavy housework, driving, shopping, walking up and down stairs, or walking half a mile). Scores for both ADLs and IADLs were dichotomized: none (0) versus 1 or more (1). Cognitive status was assessed using the 30-item Mini Mental State Examination (MMSE). Higher values indicate better cognitive functioning [25, 26]. Depressive symptoms were recorded using the 20-item Center for Epidemiologic Studies Depression (CES-D) Scale. Higher values indicate more symptoms of depression [27-29]. The two CES-D questions corresponding to the exhaustion item in the frailty index were removed from the total CES-D score in the final comprehensive statistical model (see description of model 3 below). Lastly, participants were asked to rate their overall health on a scale from 1 to 4: poor, fair, good, or excellent.

\section{Statistical Analysis}

Univariate analyses were performed relative to the two-level mortality variable: survived versus died. Statistical significance was evaluated using independent $t$ tests and the $\chi^{2}$ test for continuous and categorical variables, respectively. A cumulative survival curve was constructed to display relative mortality over time among the three levels of frailty. A series of Cox proportional hazard models was used to estimate frailty-related hazard ratios (HR) for mortality over the 10 -year study period. Surviving participants lost to or declining follow-up were censored to the date of their most recently completed interview. Model 1 included the 3level frailty classification. Model 2 added sociodemographic information: age, gender, and marital status. Model 3 further included health risk and medical condition factors: BMI, smoking status, heart attack, stroke, hypertension, cancer, hip fracture, diabetes, ADL and IADL limitations, cognitive function, depressive symptoms, and self-rated health. Lastly, separate Cox proportional hazard models were computed to estimate the unadjusted 10year mortality HR associated with each of the 5 frailty index items. All statistical tests were conducted using SPSS (version 14.0), were two-sided, and were based on a $\mathrm{p}<0.05$ significance level.

\section{Results}

Table 1 describes the item criteria for the frailty index and displays the prevalence of positive ratings for each of the five items.
Table 1. Description and prevalence of frailty index items $(\mathrm{n}=$ 1,996)

\begin{tabular}{|c|c|c|}
\hline Index item & Definition & $\%$ \\
\hline $\begin{array}{l}\text { Weight } \\
\text { loss }\end{array}$ & $\begin{array}{l}\text { Weight loss was evaluated as the change in } \\
\text { body weight over the preceding year. } \\
\text { Subjects with unintentional weight loss of } \\
4.5 \text { or more kilograms received a score of } 1 .\end{array}$ & 18.8 \\
\hline Exhaustion & $\begin{array}{l}\text { Exhaustion was measured using two ques- } \\
\text { tions from the CES-D Scale [28]. The two } \\
\text { questions used for the current study were: } \\
\text { 'I felt that everything I did was an effort' } \\
\text { and 'I could not get going.' Participants } \\
\text { reporting yes for a moderate amount or } \\
\text { most of the time over the previous week on } \\
\text { either question received a score of } 1 \text {. }\end{array}$ & 13.5 \\
\hline
\end{tabular}

\begin{tabular}{lll}
\hline Walking Walking speed was recorded during a 4.9- 21.9 &
\end{tabular}

speed meter timed walk test. Participants were instructed to walk as fast as they felt safe. Participants unable to complete the walk or who scored in the slowest quintile based on gender- and height-specific thresholds received a score of 1 :

slowest $20 \%$ for men:

$\geq 11.2 \mathrm{~s}$ for height $\leq 168 \mathrm{~cm}$

$\geq 9.7 \mathrm{~s}$ for height $>168 \mathrm{~cm}$

slowest 20\% for women:

$\geq 12.0 \mathrm{~s}$ for height $\leq 154 \mathrm{~cm}$

$\geq 11.2 \mathrm{~s}$ for height $>154 \mathrm{~cm}$

Grip Grip strength was quantified with a hand

strength dynamometer. Two trials were performed with the best effort recorded. Those unable to perform the test or those scoring in the lowest quintile based on gender- and BMIspecific criteria received a score of 1 : weakest $20 \%$ for men: $\leq 21 \mathrm{~kg}$ for $\mathrm{BMI} \leq 24.2$

$\leq 24.5 \mathrm{~kg}$ for BMI $24.3-26.8$ $\leq 25.4 \mathrm{~kg}$ for BMI $26.9-29.5$ $\leq 25.5 \mathrm{~kg}$ for $\mathrm{BMI}>29.5$ weakest $20 \%$ for women: $\leq 13.5 \mathrm{~kg}$ for $\mathrm{BMI} \leq 24.7$ $\leq 14.2 \mathrm{~kg}$ for BMI $24.8-28.3$ $\leq 15.0 \mathrm{~kg}$ for BMI 28.4-32.1 $\leq 15.0 \mathrm{~kg}$ for $\mathrm{BMI}>32.1$

Physical Physical activity was assessed using the 16.8 activity Physical Activity Scale for the Elderly (PASE), a validated self-report measure of physical activity [45]. Participants scoring in the lowest 20th percentile by gender received a score of 1 : lowest $20 \%$ for men $\leq 30$ lowest $20 \%$ for women $\leq 27.5$ 
Table 2. Sample characteristics at baseline stratified by 10 -year survival status: mean \pm SD or percent

\begin{tabular}{|c|c|c|c|c|}
\hline & Total $(\mathrm{n}=1,996)$ & Survived $(\mathrm{n}=1,104)$ & Died $(n=892)$ & $\mathrm{p}$ value \\
\hline Age, years & $74.50 \pm 6.06$ & $72.63 \pm 4.81$ & $76.81 \pm 6.62$ & $<0.001$ \\
\hline BMI & $28.05 \pm 5.26$ & $28.60 \pm 4.99$ & $27.37 \pm 5.50$ & $<0.001$ \\
\hline Grip, kg & $24.11 \pm 8.52$ & $24.92 \pm 8.53$ & $23.08 \pm 8.40$ & $<0.001$ \\
\hline Walk, s & $8.95 \pm 4.53$ & $8.27 \pm 3.60$ & $9.88 \pm 5.42$ & $<0.001$ \\
\hline PASE score & $92.63 \pm 63.08$ & $104.00 \pm 60.07$ & $78.56 \pm 63.91$ & $<0.001$ \\
\hline Duration, years & $6.97 \pm 2.62$ & $8.20 \pm 1.62$ & $5.46 \pm 2.82$ & $<0.001$ \\
\hline CES-D & $6.63 \pm 7.91$ & $5.70 \pm 7.25$ & $7.79 \pm 8.52$ & $<0.001$ \\
\hline MMSE & $24.03 \pm 4.22$ & $24.71 \pm 4.08$ & $23.20 \pm 4.25$ & $<0.001$ \\
\hline Male & 41.5 & 36.7 & 47.4 & $<0.001$ \\
\hline Married & 54.2 & 58.7 & 48.7 & $<0.001$ \\
\hline Heart attack & 8.9 & 7.6 & 10.6 & 0.023 \\
\hline Stroke & 7.1 & 5.1 & 9.5 & $<0.001$ \\
\hline Hypertension & 45.8 & 42.7 & 49.7 & 0.002 \\
\hline Cancer & 6.4 & 4.4 & 8.9 & $<0.001$ \\
\hline Hip fracture & 1.4 & 0.7 & 2.1 & 0.007 \\
\hline Diabetes & 28.2 & 23.4 & 34.1 & $<0.001$ \\
\hline Smoker & 11.6 & 10.1 & 13.6 & 0.015 \\
\hline ADL limitation & 7.7 & 2.7 & 13.9 & $<0.001$ \\
\hline IADL limitation & 46.3 & 37.2 & 57.5 & $<0.001$ \\
\hline Self-rated health & & & & $<0.001$ \\
\hline Excellent & 12.7 & 15.2 & 9.6 & \\
\hline Good & 30.6 & 31.2 & 29.8 & \\
\hline Fair & 42.7 & 44.7 & 40.2 & \\
\hline Poor & 14.0 & 8.9 & 20.3 & \\
\hline Weight loss & 18.8 & 15.4 & 23.2 & $<0.001$ \\
\hline Exhaustion & 13.5 & 9.7 & 18.2 & $<0.001$ \\
\hline Weak grip & 20.9 & 14.4 & 29.0 & $<0.001$ \\
\hline Slow walk & 21.9 & 15.6 & 30.4 & $<0.001$ \\
\hline Low activity & 16.8 & 9.1 & 26.5 & $<0.001$ \\
\hline Non-frail & 44.9 & 53.9 & 33.7 & $<0.001$ \\
\hline Pre-frail & 47.3 & 43.9 & 51.6 & 0.001 \\
\hline Frail & 7.8 & 2.2 & 14.7 & $<0.001$ \\
\hline
\end{tabular}

ADL/IADL limitation = One or more self-reported problems with ADL/IADL; PASE = Physical Activity Scale for the Elderly. Univariate tests of significance were performed with independent $t$ tests for continuous variables and $\chi^{2}$ tests for categorical variables.

Nearly $45 \%$ of all participants died during the 10 -year study period. Calculating the (unadjusted) percentage of deaths within each of the three frailty categories shows a stepwise increase in mortality: non-frail (33.6\%), pre-frail (48.7\%), and frail (84.5\%).

Baseline sociodemographic characteristics and healthrelated factors stratified by 10 -year survival status are shown in table 2. Univariate analysis revealed significant relationships between 10 -year mortality and all sociodemographic and health-related covariates included in this study. Regarding the primary objective of the study, both pre-fail and frail categories were positively associated with mortality, while those classified as non-frail at base- line experienced significantly less mortality over the 10year study period.

Figure 1 shows the unadjusted association between frailty categories and 10-year survival rate. Using the 8year mark as an example, the curves reveal that $73 \%$ of those classified as non-frail at baseline were still alive 8 years later. In contrast, only $61 \%$ and $27 \%$ of older Mexican Americans in the pre-frail and frail categories, respectively, survived at least 8 years past baseline.

The independent association between baseline frailty status and 10-year mortality was evaluated via a series of three Cox proportional hazard models. Table 3 shows the HR from each model with the successive addition of 


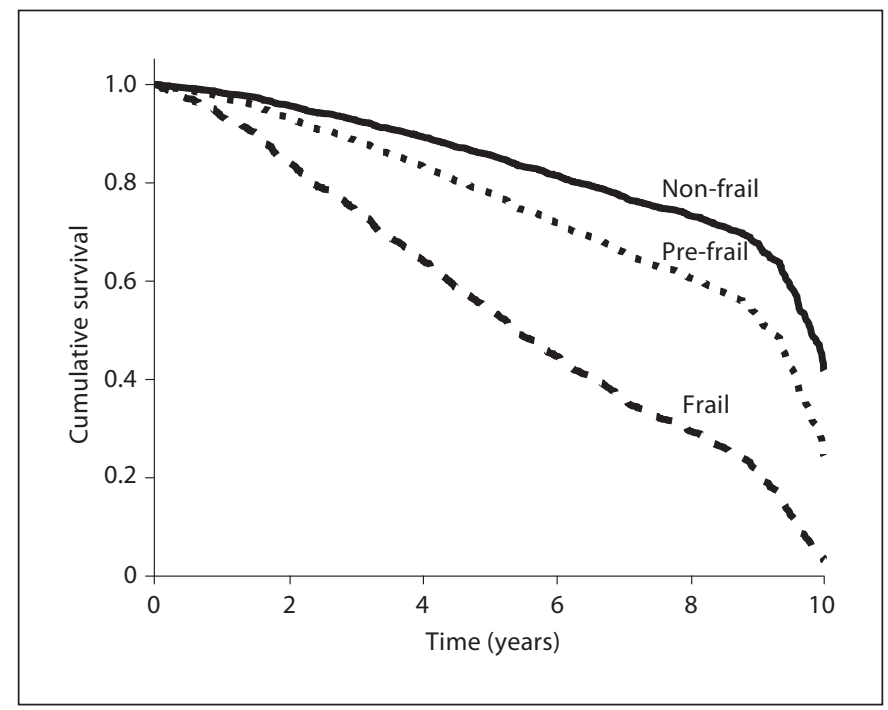

Fig. 1. Survival curve by baseline frailty categories $(n=1,996)$.

covariates that are likely to affect survival. All three models demonstrated statistically significant increases in HR for death among pre-frail and frail categories relative to the non-frail group. Model 3, while controlling for sociodemographic characteristics, health-related factors, and medical conditions, demonstrates that the prefrail group experienced 1.25 times (95\% confidence interval, $\mathrm{CI}_{95 \%}, 1.07-1.46$ ) the odds of mortality relative to the non-frail group. The group classified as frail at baseline demonstrated increased odds of $1.81\left(\mathrm{CI}_{95 \%} 1.41-\right.$ 2.31).

Figure 2 shows the unadjusted $\mathrm{HR}$ and $\mathrm{CI}_{95 \%}$ for the association between 10-year survival and each of the 5 items included in the frailty index. Low physical activity demonstrated the strongest relationship, followed by slow walking speed, weak grip strength, exhaustion, and weight loss.

\section{Discussion}

The results supported our hypothesis that frailty status is associated with increased 10-year mortality in older Mexican Americans. Cox proportional hazard models adjusted for sociodemographic characteristics, health-related factors, and medical conditions revealed increased odds of 1.3 and 1.8 for those classified as pre-frail and frail, respectively, at baseline compared to the non-frail cohort.

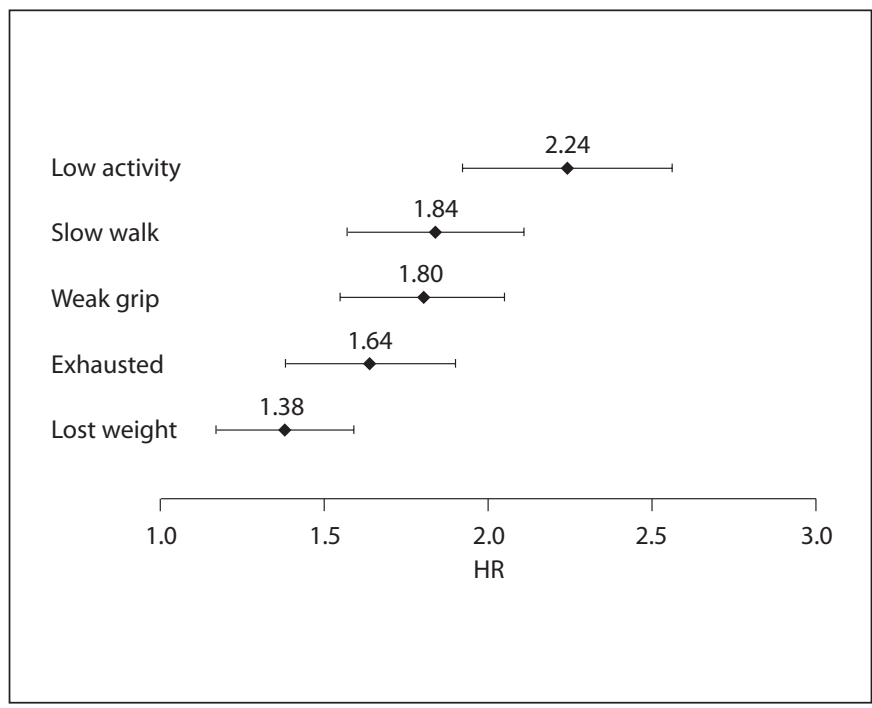

Fig. 2. Individual unadjusted $\mathrm{HR}$ and $\mathrm{CI}_{95 \%}$ for 10 -year mortality by each item in frailty index $(n=1,996)$.

The original study using the 5-item frailty index, adopted for the current investigation, assessed 7-year mortality relative to frailty status in a large sample of older, mostly (85\%) Caucasian, community-dwelling participants [15]. Compared to the non-frail group, the adjusted HR from that study were 1.3 and 1.6 for baseline pre-frail and frail categories, respectively. These values are similar to the 10-year odds of death in the current study (table 3): pre-frail $(\mathrm{HR}=1.3)$ and frail $(\mathrm{HR}=1.8)$. Rockwood et al. [11] evaluated 5-year mortality in older adults using a 4category frailty scale developed from the geriatric status scale, an instrument originally designed to assess specialty care needs for hospitalized patients. Mortality HR (adjusted for age and sex only) in that study ranged from 1.2 to 3.1 .

Other studies have investigated the relationships between unidimensional aspects of health or functioning and mortality in older Mexican Americans. Both static BMI [18] and dynamic weight change (2-year weight loss $>5 \%$ ) [30], for example, are significantly associated with mortality over 7 and 5 years, respectively. Likewise, poor grip strength is an independent predictor of 5-year mortality in older Mexican Americans [31]. Ostir et al. [32] recently showed a significant relationship between a composite measure of lower-extremity functional performance (Short Physical Performance Battery) and 7-year mortality in non-disabled older Mexican Americans. The HR, obtained in their model with similar adjustments for baseline characteristics as the current study, 
Table 3. Cox proportional hazard models for 10 -year mortality $(n=1,996)$

\begin{tabular}{|c|c|c|c|c|c|c|}
\hline & \multicolumn{2}{|c|}{ Model 1} & \multicolumn{2}{|c|}{ Model 2} & \multicolumn{2}{|c|}{ Model 3} \\
\hline & HR & $\mathrm{CI}_{95 \%}$ & $\mathrm{HR}$ & $\mathrm{CI}_{95 \%}$ & HR & $\mathrm{CI}_{95 \%}$ \\
\hline \multicolumn{7}{|l|}{ Frailty index } \\
\hline Non-frail & \multicolumn{2}{|c|}{1.00} & \multicolumn{2}{|c|}{1.00} & \multicolumn{2}{|c|}{1.00} \\
\hline Pre-frail & 1.57 & $1.36,1.83$ & 1.45 & $1.24,1.68$ & 1.25 & $1.07,1.46$ \\
\hline Frail & 3.77 & $3.05,4.65$ & 2.68 & $2.14,3.34$ & 1.81 & $1.41,2.31$ \\
\hline Age & & & 1.06 & $1.05,1.08$ & 1.06 & $1.05,1.07$ \\
\hline Male & & & 1.71 & $1.47,1.98$ & 1.77 & $1.50,2.08$ \\
\hline Married & & & 0.82 & $0.70,0.95$ & 0.87 & $0.75,1.02$ \\
\hline BMI & & & & & 0.98 & $0.97,0.99$ \\
\hline Smoker & & & & & 1.42 & $1.15,1.76$ \\
\hline Heart attack & & & & & 0.97 & $0.77,1.22$ \\
\hline Stroke & & & & & 1.23 & $0.97,1.55$ \\
\hline Hypertension & & & & & 1.30 & $1.13,1.51$ \\
\hline Cancer & & & & & 1.57 & $1.23,2.01$ \\
\hline Hip fracture & & & & & 1.23 & $0.75,2.00$ \\
\hline Diabetes & & & & & 1.47 & $1.27,1.71$ \\
\hline ADL limitation & & & & & 1.45 & $1.15,1.82$ \\
\hline IADL limitation & & & & & 1.35 & $1.15,1.59$ \\
\hline CES-D (18 items & & & & & 1.00 & $0.99,1.01$ \\
\hline MMSE & & & & & 0.98 & $0.97,1.00$ \\
\hline Self-rated health, & cellent & & & & 1.08 & $0.93,1.26$ \\
\hline
\end{tabular}

ranged from 1.2 to 1.6. Unlike these unidimensional measures, the 5 -item frailty index contains both objective and self-reported measures of physical functioning, which are complimentary - not interchangeable - measures of physical abilities [33, 34].

Markides et al. [35] showed that composite scores from an objective (the Short Physical Performance Battery) and subjective (self-reported limitations in ADL) measure of physical functioning were significantly associated with 2-year mortality in older Mexican Americans. In addition, when both measures were included in the same model, only the objective measure remained significantly associated with mortality.

Gill et al. [16], using the same 5 frailty index categories as the current study, reported significant unadjusted associations between all 5 items and mortality over a 6-year follow-up period in older, non-disabled, and predominantly $(90 \%)$ non-Hispanic white participants. The relationship between the composite frailty scale and mortality was not explored. The unadjusted HR for the individual items in their study were as follows: 1.9 (weak grip strength), 2.0 (exhaustion), 2.0 (weight loss), 2.3 (slow walking speed), and 2.8 (low physical activity). Those values are generally higher than those obtained in the current analysis involving older Mexican Americans (fig. 2).
Another study by Purser et al. [36] compared the relative ability of two different composite frailty indices and three single-item measures to predict 2-year mortality in hospitalized older adults with coronary artery disease. Interestingly, both slow gait speed and poor grip strength showed trends toward stronger predictions of 6-month mortality than dichotomized scores (frail versus non-/ pre-frail) from the 5-item Fried frailty index. The large and skewed confidence intervals, however, make it difficult to draw solid conclusions: gait speed odds ratio $(\mathrm{OR})=3.8, \mathrm{CI}_{95 \%}=1.1-13.1$; grip strength $\mathrm{OR}=2.7$, $\mathrm{CI}_{95 \%}=0.7-10.0$, and composite frailty $\mathrm{OR}=1.9, \mathrm{CI}_{95 \%}=$ $0.6-6.1[36]$.

From a clinical standpoint, it is important to go beyond measurement and focus on management. Frailty is a complex and dynamic state that is influenced by social and environmental factors [37] and should be responsive to restorative and prevention strategies $[16,38]$. While physical activity and exercise programs are widely acknowledged as effective means for maintaining health and functioning in aging, it is also important to consider the implications of active interventions in those demonstrating signs and symptoms of physical impairment. The initial subclinical stage of pre-frail suggests that this construct is conducive to early detection and effective in- 
tervention opportunities for those at risk of functional decline $[32,39]$. Two prior studies have demonstrated that frail individuals can also participate in and receive positive benefits from active intervention [40, 41]. Although mortality was not an outcome in either study, based on the current results it is logical to assume that an intervention capable of halting, or reversing, the frailty process would have a subsequent impact on a person's risk for adverse health outcomes, including death.

The current results also show that men had increased odds of mortality compared to women even after controlling for other sociodemographic factors, health-related characteristics, and frailty (table 3, model 3). It is generally acknowledged that the additional years of life that women experience compared to men are typically marked by increasing functional limitations. In other words, despite consistent gender differences in total life expectancy across age groups, active (or disability-free) life expectancy does not differ by sex [42]. Additional studies are warranted to assess gender-specific associations between frailty (i.e. pre-clinical disability) and mortality among older Mexican Americans and to identify the characteristics and circumstances contributing to this relationship.

The current study has several limitations including the use of self-reported medical conditions. Although there is no reason to assume inaccuracy or bias from the participants, it is generally acknowledged that objective data from medical records and a standardized evaluation are preferred to patient recall or self-assessment. Substantial agreement between self-reported disease and medical record diagnosis has been documented [43]. Our sample contained only community-dwelling participants and did not include persons in nursing homes or other institutional environments. In addition, we excluded persons from the original Hispanic EPESE sample who completed the interview with the assistance of a proxy, or who had missing data on more than two components of the frailty index. In general, these persons had more disability and a higher number of comorbidities than the persons included in the final sample. Thus, the associations reported in this study may not characterize the 'frailest' of older persons (e.g. those in institutional care) and likelarge, community-based sample of older Mexican Americans provides a comprehensive picture of functioning within this population. The 10 -year longitudinal design

health-related outcomes. This is also the first study, to our knowledge, to evaluate the relationship between frailty and mortality in a representative sample of older Mexican Americans.

In summary, the current findings demonstrated that a 5 -item frailty index differentiated odds of mortality in a large sample of community-dwelling Mexican American older adults. Similar observations have been reported in non-minority elderly. Previous research suggests that appropriate interventions can slow or even reverse the frailty process [41]. Thus, the frailty index used in this study may provide an efficient and informative clinical indicator to help identify older Mexican Americans at risk for functional decline and who would benefit from targeted intervention. This is of particular importance based on the evidence that Hispanics, in general, are at greater risk of preventable hospitalizations than non-Hispanic whites for a variety of primary care-amenable conditions [44]. Further study is necessary to clarify genderspecific risk factors for frailty and unique gender-based associations between frailty and other poor health outcomes and to determine if interventions to improve frailty translate to increased longevity within the expanding Mexican American older adult population.

\section{Acknowledgments}

The study was supported by the National Institute on Aging (R01-AG10939 to K.S.M., and R01-AG17638 and K02-AG019736t to K.J.O.); the National Institutes of Health (K12-HD052023 to S.A.S. and R03-HD05821601 to I.M.B.), and the National Institute on Disability and Rehabilitation Research (H133P040003 to J.E.G.). ly underestimates the relationship between frailty and mortality in older Mexican Americans.

This study includes several strengths. The use of a represents a powerful study methodology to investigate

References
Gerontology 2009;55:644-651
1 Field MJ, Jette AM: The Future of Disability in America. Washington, National Academies Press, 2007.

2 US Census Bureau: US Interim Projections by Age, Sex, Race, and Hispanic Origin. Available: http://www.census.gov/population/www/projections/usinterimproj/ 2008 (accessed August 5, 2009).

3 Congressional Budget Office: Projections of expenditures for long-term care services for the elderly. Available: http://www.cbo.gov/ ftpdocs/11xx/doc1123/ltcare.pdf 1999 (accessed August 5, 2009).

4 US Census Bureau: 2000 Census of Population and Housing. Washington, US Census Bureau, 2002.
Graham/Snih/Berges/Ray/Markides/ Ottenbacher 
5 Berkman CS, Gurland BJ: The relationship between ethnoracial group and functional level in older persons. Ethn Health 1998;3: $175-188$.

6 Centers for Disease Control: Disability and Secondary Conditions HP2010 Focus Area 6:2002 Forum and 2001 Symposium proceedings. http://www.cdc.gov/ncbddd/dh/ publications/FocusArea6PDFforWeb8_03. pdf 2003 (accessed August 5, 2009).

7 Markides KS: Encyclopedia of Health \& Aging. Los Angeles, Sage Publications, 2007.

-8 Bortz WM: A conceptual framework of frailty: a review. J Gerontol A Biol Sci Med Sci 2002;57:M283-M288.

-9 Levers MJ, Estabrooks CA, Ross Kerr JC: Factors contributing to frailty: literature review. J Adv Nurs 2006;56:282-291.

10 Markle-Reid M, Browne G: Conceptualizations of frailty in relation to older adults. J Adv Nurs 2003;44:58-68.

-11 Rockwood K, Stadnyk K, MacKnight C, et al: A brief clinical instrument to classify frailty in elderly people. Lancet 1999;353:205-206.

$\checkmark 12$ Rockwood K, Hogan DB, MacKnight C: Conceptualisation and measurement of frailty in elderly people. Drugs Aging 2000; 17:295-302.

13 Cohen HJ: In search of the underlying mechanisms of frailty. J Gerontol A Biol Sci Med Sci 2000;55:M706-M708.

14 Mitnitski AB, Graham JE, Mogilner AJ, et al: Frailty, fitness and late-life mortality in relation to chronological and biological age. BMC Geriatr 2002;2:1.

15 Fried LP, Tangen CM, Walston J, et al: Frailty in older adults: evidence for a phenotype. J Gerontol A Biol Sci Med Sci 2001;56:M146M156.

16 Gill TM, Gahbauer EA, Allore HG, et al: Transitions between frailty states among community-living older persons. Arch Intern Med 2006;166:418-423.

-17 Al Snih S, Raji MA, Markides KS, et al: Weight change and lower body disability in older Mexican Americans. J Am Geriatr Soc 2005;53:1730-1737.

$\checkmark 18$ Al Snih S, Ottenbacher KJ, Markides KS, et al: The effect of obesity on disability vs mortality in older Americans. Arch Intern Med 2007; 167:774-780.

19 Markides KS, Rudkin L, Angel RJ, et al: Health status of Hispanic elderly; in Martin LG, Soldo BJ (eds): Racial and Ethnic Differences in the Health of Older Americans. Washington, National Academies Press, 1997, pp 285-300.
20 Markides KS, Stroup-Benham CA, Black SA, et al: The health of Mexican American Elderly: selected findings from the Hispanic EPESE; in Wykle ML, Ford AB (eds): Serving Minority Elders in the Twenty-First Century. New York, Springer, 1999, pp 72-90.

21 Taylor HL, Jacobs DR Jr, Schucker B, et al: A questionnaire for the assessment of leisure time physical activities. J Chronic Dis 1978; 31:741-755.

22 Washburn RA, Smith KW, Jette AM, et al: The Physical Activity Scale for the Elderly (PASE): development and evaluation. J Clin Epidemiol 1993;46:153-162.

23 Gillum RF, Sempos CT: Ethnic variation in validity of classification of overweight and obesity using self-reported weight and height in American women and men: the Third National Health and Nutrition Examination Survey. Nutr J 2005;4:27.

24 Ogden CL, Carroll MD, Curtin LR, et al: Prevalence of overweight and obesity in the United States, 1999-2004. JAMA 2006;295: 1549-1555.

25 Bird HR, Canino G, Stipec MR, et al: Use of the Mini-Mental State Examination in a probability sample of a Hispanic population. J Nerv Ment Dis 1987;175:731-737.

26 Uhlmann RF, Larson EB: Effect of education on the Mini-Mental State Examination as a screening test for dementia. J Am Geriatr Soc 1991:39:876-880

27 Heikkinen RL, Kauppinen M: Depressive symptoms in late life: a 10-year follow-up. Arch Gerontol Geriatr 2004;38:239-250.

28 Roberts RE: Reliability of the CES-D Scale in different ethnic contexts. Psychiatry Res 1980;2:125-134.

29 Radloff LS: The CES-D Scale: A self-report depression scale for research in the general population. Appl Psychol Meas 1977;1:385401.

30 Amador LF, Al Snih S, Markides KS, et al: Weight change and mortality among older Mexican Americans. Aging Clin Exp Res 2006;18:196-204.

31 Al Snih S, Markides KS, Ray L, et al: Handgrip strength and mortality in older Mexican Americans. J Am Geriatr Soc 2002;50:12501256.

-32 Ostir GV, Kuo YF, Berges IM, et al: Measures of lower body function and risk of mortality over 7 years of follow-up. Am J Epidemiol 2007; 166:599-605.

33 Puts MT, Lips P, Deeg DJ: Static and dynamic measures of frailty predicted decline in performance-based and self-reported physical functioning. J Clin Epidemiol 2005;58: 1188-1198.
34 Guralnik JM, Ferrucci L, Pieper CF, et al: Lower extremity function and subsequent disability: consistency across studies, predictive models, and value of gait speed alone compared with the short physical performance battery. J Gerontol A Biol Sci Med Sci 2000;55:M221-M231.

35 Markides KS, Black SA, Ostir GV, et al: Lower body function and mortality in Mexican American elderly people. J Gerontol A Biol Sci Med Sci 2001;56:M243-M247.

-36 Purser JL, Kuchibhatla MN, Fillenbaum GG, et al: Identifying frailty in hospitalized older adults with significant coronary artery disease. J Am Geriatr Soc 2006;54:1674-1681.

37 Woo J, Goggins W, Sham A, et al: Social determinants of frailty. Gerontology 2005;51: 402-408.

38 Ferrucci L, Guralnik JM, Studenski S, et al: Designing randomized, controlled trials aimed at preventing or delaying functional decline and disability in frail, older persons: a consensus report. J Am Geriatr Soc 2004; 52:625-634.

39 Fried LP, Ferrucci L, Darer J, et al: Untangling the concepts of disability, frailty, and comorbidity: implications for improved targeting and care. J Gerontol A Biol Sci Med Sci 2004;59:255-263.

40 Chandler JM, Duncan PW, Kochersberger $\mathrm{G}$, et al: Is lower extremity strength gain associated with improvement in physical performance and disability in frail, community-dwelling elders? Arch Phys Med Rehabil 1998; 79:24-30

41 Villareal DT, Banks M, Sinacore DR et al: Effect of weight loss and exercise on frailty in obese older adults. Arch Intern Med 2006; 166:860-866

42 Reyes-Beaman S, Jagger C, Garcia-Peña C, et al: Active life expectancy of older people in Mexico. Disabil Rehabil 2005;27:213-219.

43 Okura Y, Urban LH, Mahoney DW, et al: Agreement between self-report questionnaires and medical record data was substantial for diabetes, hypertension, myocardial infarction and stroke but not for heart failure. J Clin Epidemiol 2004;57:1096-1103.

44 Laditka JN, Laditka SB: Race, ethnicity and hospitalization for six chronic ambulatory care sensitive conditions in the USA. Ethn Health 2006;11:247-263.

45 Washburn RA, McAuley E, Katula J, et al: The physical activity scale for the elderly (PASE): evidence for validity. J Clin Epidemiol 1999;52:643-651. 